\title{
SPECIAL ISSUE EDITORIAL: CONSTRUCTION 4.0: ESTABLISHED AND EMERGING DIGITAL TECHNOLOGIES WITHIN THE CONSTRUCTION INDUSTRY
}

PUBLISHED: November 2021

DOI: $10.36680 /$ j.itcon.2021.041

Nashwan Dawood

School of Computing, Engineering \& Digital Technologies, Teesside University, Middlesbrough, UK; n.n.dawood@tees.ac.uk

\section{Farzad Pour Rahimian}

School of Computing, Engineering \& Digital Technologies, Teesside University, Middlesbrough, UK; f.rahimian@tees.ac.uk

Despite its significant impact on industrial employment (i.e. over $6.6 \%$ contribution) and representation of $9.8 \%$ of the UK's Gross Domestic Product (Rhodes, 2019), the AEC industry has been continuously criticised due to its fragmentation for over five decades that resulted in several major industry reports. The knowledge gap between design and construction has been identified by many studies as a major reason for this discontinuity (Abrishami et al., 2014; Fruchter et al., 2016; Goulding and Pour Rahimian, 2019; Goulding et al., 2015; Pour Rahimian et al., 2019; Pour Rahimian et al., 2008; Rahimian et al., 2011).

Meanwhile, the wider world (including the built environment) is experiencing a kind of paradigm shift due to the emergence of the industry 4.0 revolution. Recent technological and other process-based advances and innovative technologies in the built environment mentioned above have a key role to play in this process. As widely reported in the popular and scientific media, the nine pillars supporting Industry 4.0 are 1) The Internet of Things, 2) Big Data, 3) Augmented Reality, 4) Advanced Visualisation, VR and Simulation, 5) Additive Manufacturing, 6) System Integration, 7) Cloud Computing, 8) Autonomous Systems, and 9) Cybersecurity.

In the case of the built environment sector, these nine pillars can be said to be underpinned by BIM, widely regarded as the tool of choice to address key issues as industry fragmentation, value-driven solutions, decision making, client engagement, and design/process flow to name but a few. Therefore, it could be argued that Construction 4.0 has ten pillars which include the nine Industry 4.0 pillars and BIM. Exemplars from other industries such as automotive, aerospace and oil and gas currently demonstrate the power and application of these technologies. However, the built environment has only just started to recognise terms such as "golden key" and "golden thread" as part of BIM processes and workflows. Construction 4.0 offers a portfolio of potential solutions to bridge the knowledge and information gaps between design, construction and operations (Gomez-Trujillo and Gonzalez-Perez, 2021; Newman et al., 2020; Sawhney et al., 2020).

This has led to the emergence of a series of cutting edge technologies in the AEC realm, including but not limited to virtual reality-based collaboration technologies (Pour Rahimian et al., 2019), artificial intelligence-based optimisation (Pilechiha et al., 2020), data-driven decision support (Seyedzadeh et al., 2019), smart data modelling (Seyedzadeh et al., 2020), blockchain and distributed ledger technologies (Alizadehsalehi and Yitmen, 2021; Brandín and Abrishami, 2021; Elghaish et al., 2020; Wong et al., 2020), and computer vision and graphics (Moshtaghian et al., 2020; Pour Rahimian et al., 2020). Where for example, these advancements are now able to assist decision-making in predicting the cost and performance of optimal design proposals (Elghaish and Abrishami, 2020).

Distributed ledger technologies complement these advancements by introducing consensus-based decisionmaking, removing the social identity and bad faith communications at the heart of many disruptive conflicts in a collaborative project (Jaffar et al., 2011). Advancements in cryptography and read-only data management optimisation are paving the way for fully-fledged distributed ledger technologies for digital twinning and asset lifecycle management (Alizadehsalehi and Yitmen, 2021; Ogunseiju et al., 2021b). Previous research has demonstrated real-time centralised solutions for OpenBIM. Research has begun to demonstrate the feasibility of 
decentralising these OpenBIM systems (Oliver et al., 2020). Collectively, these developments are forcing a paradigm shift in design from asynchronous to real-time data exchanges, which are impervious to repudiation, ultimately improving inter-organisational perceptions of social presence (Oliver, 2019) and imbuing confidence in the design shift expected of OpenBIM.

As a reflection on the issues discussed above, this special issue of ITCON brought together ten papers on Construction 4.0 related topics. These papers are drawn from papers presented at the $20^{\text {th }}$ International Conference on Construction Applications of Virtual Reality (CONVR 2021) held at Teesside University, Middlesbrough TS1 $3 \mathrm{JN}$, the UK, in October 2020. CONVR is one of the world-leading conferences in the areas of Virtual Reality, augmented reality and building information modelling. Each year, more than 100 participants from all around the globe meet to discuss and exchange the latest developments and applications of virtual technologies in the architectural, engineering, construction and operation industry (AECO). The conference is also known for having a unique blend of participants from both academia and industry. The overarching theme for CONVR2020 was "Enabling the development and implementation of Digital Twins."

Tallgren et al. (2021) mapped collaborative planning and scheduling methods and traditional 4D scheduling using process modelling. This mapping is followed by implementing the 4D collaborative planning and scheduling method in the virtual project planning system with support for a multi-user interactive VR environment. Pidgeon and Dawood (2021) presented a systematic review of academic and industrial literature to define a common meaning of collaborative BIM through the development of syntax to support a hypothetical infrastructure project utilising academic and industry BIM experts. This was followed by bringing to the front the inefficiencies in their current form and defining how the fundamental parts of BIM are assigned and then prioritised qualitatively and quantitively to enhance information clarity (goals and objective achievement) and inconsistency reduction towards better ways of implementation.

Reyes-Veras et al. (2021) argued that the adoption of Big Data in the construction industry had been identified as a possible solution to the demand of the current needs of projects, but the integration of this technology has proven to be a challenge, especially in industries such as construction that are not technological driven. They aimed to explore the challenges faced by the adoption of BD in the Dominican Republic construction industry. Al-Sehrawy et al. (2021) affirm that the knowledge created under Digital Twin real-world implementation comprises the 'know-how' and genuine practical experience upon undertaking various Digital Twin pilot projects, case studies, and proof-of-concept initiatives which the Digital Twin research and practices can further develop and mature. They conclude with an overview of the implications of Digital Twin Uses Classification System along with recommendations on how it can be further validated and improved.

Inspired by opportunities offered by mixed reality, Ogunseiju et al. (2021a) presented the development and evaluation of a holographic learning environment that can afford learners an experiential opportunity to acquire competencies for implementing sensing systems on construction projects. To develop the content of the learning environment, they surveyed construction industry practitioners and instructors, and explored construction industry case studies on the applications of sensing technologies. Shojaei et al. (2021) investigated a pilot experiment where a combination of 360,180 3D, and flat videos was incorporated as an educational instrument in delivering construction management content. Their results showed a positive perception toward using immersive videos in construction education. As a result, they concluded that the prospect of incorporating immersive videos to enhance construction management education is promising.

Khanna et al. (2021) investigated the feasibility of implementing IPD approach and applying its principles. They assessed the maturity of delivery techniques, and the potential benefits and limitations of using IPD for infrastructure projects in developing countries, using India as a case study. They recommended that the regulatory bodies must establish governing standards and frameworks, amend regulations to accept IPD concepts, and upskill the workforce through training and knowledge transfer for its successful adoption. Dalui et al. (2021) aimed to identify the advantages and limitations in the implementation of the Building Information Modelling (BIM) and Integrated Project Delivery (IPD) in the UK consulting sector. They recommended that schools take steps to improve career advice and guidance for students in relation to construction, specifically increasing awareness of the opportunities available related to BIM and working professionals to increase awareness of and employment in BIM through training and apprentices as appropriately. 
Gonsalves et al. (2021) presented the assessment of a commercially available passive wearable robot, BackX, designed for reducing low back disorder amongst rebar workers. The study evaluated the exoskeleton in terms of task performance and physiological conditions. Outcome measures such as completion time were employed to evaluate the effect of the exoskeleton on task performance, while activations of Erector Spinae and Latissimus Dorsi muscles, and perceived discomfort across body parts were employed to assess the physiological effects of the exoskeleton. Chowdhury et al. (2021) asserted that the views of web-based tool users in terms of functionality, potency and usability of the various platforms are often neglected. They anticipate that if web-based collaboration is to be further enhanced, the views of users must be known. The study explored Financeonline's top six tools CoCostruct, PlanGrid, Autodesk BIM 360, Procore, e-builder and Aconex. The results of their study highlighted that while $70 \%$ of user reviews of web-based collaborative tools are positive, there remains much room for improvement.

\section{REFERENCES}

Abrishami, S., Goulding, J., Rahimian, F. P., \& Ganah, A. (2014). Integration of BIM and generative design to exploit AEC conceptual design innovation. Information Technology in Construction, 19, 350-359.

Al-Sehrawy, R., Kumar, B., \& Watson, R. (2021). A Digital Twin Uses Classification System for Urban Planning \& City Infrastructure Management. Journal of Information Technology in Construction (ITCON), 26, 832-862, doi:10.36680/j.itcon.2021.045

Alizadehsalehi, S., \& Yitmen, I. (2021). Digital twin-based progress monitoring management model through reality capture to extended reality technologies (DRX). Smart and Sustainable Built Environment, ahead-of-print(ahead-of-print). doi:10.1108/SASBE-01-2021-0016

Brandín, R., \& Abrishami, S. (2021). Information traceability platforms for asset data lifecycle: blockchainbased technologies. Smart and Sustainable Built Environment, ahead-of-print(ahead-of-print). doi:10.1108/SASBE-03-2021-0042

Chowdhury, M., Hosseini, M. R., Martek, I., Edwards, D. J., \& Wang, J. (2021). The Effectiveness of WebBased Technology Platforms In Facilitating Construction Project Collaboration: A Qualitative Analysis of 1,152 User Reviews. Journal of Information Technology in Construction (ITCON), 26, 953-973, doi:10.36680/j.itcon.2021.051

Dalui, P., Elghaish, F., Brooks, T., \& McIlwaine, S. (2021). Integrated Project Delivery with BIM: A Methodical Approach within the UK Consulting Sector. Journal of Information Technology in Construction (ITCON), 26, 922-935, doi:10.36680/j.itcon.2021.049

Elghaish, F., \& Abrishami, S. (2020). Developing a framework to revolutionise the 4D BIM process: IPD-based solution. Construction Innovation.

Elghaish, F., Abrishami, S., \& Hosseini, M. R. (2020). Integrated project delivery with blockchain: An automated financial system. Automation in Construction, 114, 103182. doi:https://doi.org/10.1016/j.autcon.2020.103182

Fruchter, R., Herzog, S., Hallermann, N., \& Morgenthal, G. Drone Site Data for Better Decisions in AEC Global Teamwork. 16th International Conference on Computing in Civil and Building Engineering, Osaka, 2016.

Gomez-Trujillo, A. M., \& Gonzalez-Perez, M. A. (2021). Digital transformation as a strategy to reach sustainability. Smart and Sustainable Built Environment, ahead-of-print(ahead-of-print). doi:10.1108/SASBE-01-2021-0011

Gonsalves, N. J., Ogunseiju, O. R., Akanmu, A. A., \& Nnaji, C. A. (2021). Assessment of a Passive Wearable Robot for Reducing Low Back Disorders During Rebar Work. Journal of Information Technology in Construction (ITCON), 26, 936-952, doi:10.36680/j.itcon.2021.050

Goulding, J. S., \& Pour Rahimian, F. (2019). Offsite Production and Manufacturing for Innovative Construction: People, Process and Technology: Routledge. ISBN: 1351376888 
Goulding, J. S., Pour Rahimian, F., Arif, M., \& Sharp, M. D. (2015). New offsite production and business models in construction: priorities for the future research agenda. Architectural Engineering and Design Management, 11(3), 163-184. doi:10.1080/17452007.2014.891501

Jaffar, N., Tharim, A. H. A., \& Shuib, M. N. (2011). Factors of Conflict in Construction Industry: A Literature Review. Procedia Engineering, 20, 193-202. doi:https://doi.org/10.1016/j.proeng.2011.11.156

Khanna, M., Elghaish, F., McIlwaine, S., \& Brooks, T. (2021). Feasibility of Implementing IPD Approach for Infrastructure Projects in Developing Countries. Journal of Information Technology in Construction (ITCON), 26, 902-921, doi:10.36680/j.itcon.2021.048

Moshtaghian, F., Golabchi, M., \& Noorzai, E. (2020). A framework to dynamic identification of project risks. Smart and Sustainable Built Environment. doi:10.1108/SASBE-09-2019-0123

Newman, C., Edwards, D., Martek, I., Lai, J., Thwala, W. D., \& Rillie, I. (2020). Industry 4.0 deployment in the construction industry: a bibliometric literature review and UK-based case study. Smart and Sustainable Built Environment. doi:10.1108/SASBE-02-2020-0016

Ogunseiju, O. O., Akanmu, A. A., \& Bairaktarova, D. (2021a). MIXED REALITY BASED ENVIRONMENT FOR LEARNING SENSING 37 TECHNOLOGY APPLICATIONS IN CONSTRUCTION. Journal of Information Technology in Construction (ITCON), 26, 863-885, doi:10.36680/j.itcon.2021.046

Ogunseiju, O. R., Olayiwola, J., Akanmu, A. A., \& Nnaji, C. (2021b). Digital twin-driven framework for improving self-management of ergonomic risks. Smart and Sustainable Built Environment, ahead-of$\operatorname{print}($ ahead-of-print). doi:10.1108/SASBE-03-2021-0035

Oliver, S. (2019). Communication and trust: rethinking the way construction industry professionals and software vendors utilise computer communication mediums. Visualization in Engineering, 7(1), 1. doi:10.1186/s40327-019-0068-y

Oliver, S., Rahimian, F. P., Seyedzadeh, S., Rodriguez, S., \& Dawood, N. (2020). Converting open standard CAD formats into decentralised common data environments. Proceedings of CONVR 2020.

Pidgeon, A., \& Dawood, N. (2021). Bridging the Gap Between Theory and Practice for Adopting Meaningful Collaborative BIM Processes in Infrastructure Projects, Utilising Multi-Criteria Decision Making (Mcdm). Journal of Information Technology in Construction (ITCON), 26, 783-811, doi:10.36680/j.itcon.2021.043

Pilechiha, P., Mahdavinejad, M., Pour Rahimian, F., Carnemolla, P., \& Seyedzadeh, S. (2020). Multi-objective optimisation framework for designing office windows: quality of view, daylight and energy efficiency. Applied Energy, 261, 114356. doi:https://doi.org/10.1016/j.apenergy.2019.114356

Pour Rahimian, F., Chavdarova, V., Oliver, S., Chamo, F., \& Potseluyko Amobi, L. (2019). OpenBIM-Tango integrated virtual showroom for offsite manufactured production of self-build housing. Automation in Construction, 102, 1-16. doi:https://doi.org/10.1016/j.autcon.2019.02.009

Pour Rahimian, F., Ibrahim, R., \& Baharudin, M. N. Using IT/ICT as a new medium toward implementation of interactive architectural communication cultures. Proceedings - International Symposium on Information Technology 2008, ITSim, 2008. doi:10.1109/ITSIM.2008.4631984

Pour Rahimian, F., Seyedzadeh, S., Oliver, S., Rodriguez, S., \& Dawood, N. (2020). On-demand monitoring of construction projects through a game-like hybrid application of BIM and machine learning. Automation in Construction, 110, 103012. doi:https://doi.org/10.1016/j.autcon.2019.103012

Rahimian, F. P., Ibrahim, R., Rahmat, R. W. B. O. K., Abdullah, M. T. B., \& Jaafar, M. S. B. H. (2011). Mediating cognitive transformation with VR 3D sketching during conceptual architectural design process. Archnet-IJAR, 5(1), 99-113.

Reyes-Veras, P. F., Renukappa, S., \& Suresh, S. (2021). CHALLENGES FACED BY THE ADOPTION OF BIG DATA IN THE DOMINICAN REPUBLIC CONSTRUCTION INDUSTRY: AN EMPIRICAL STUDY. Journal of Information Technology in Construction (ITCON), 26, 812-831, doi:10.36680/j.itcon.2021.044 
Rhodes, C. (2019). Construction industry: statistics and policy. Retrieved from House of Commons Library: http://researchbriefings.files.parliament.uk/documents/SN01432/SN01432.pdf, Last Access:

Sawhney, A., Riley, M., \& Irizarry, J. (2020). Construction 4.0: An innovation platform for the built environment. London: Routledge. ISBN: 0429398107

Seyedzadeh, S., Pour Rahimian, F., Rastogi, P., \& Glesk, I. (2019). Tuning machine learning models for prediction of building energy loads. Sustainable Cities and Society, 47, 101484. doi:https://doi.org/10.1016/j.scs.2019.101484

Seyedzadeh, S., Rahimian, F. P., Oliver, S., Glesk, I., \& Kumar, B. (2020). Data driven model improved by multi-objective optimisation for prediction of building energy loads. Automation in Construction, 116. doi:10.1016/j.autcon.2020.103188

Shojaei, A., Rokooei, S., Mahdavian, A., Carson, L., \& Ford, G. (2021). Using Immersive Video Technology for Construction Management Content Delivery: A Pilot Study. Journal of Information Technology in Construction (ITCON), 26, 886-901, doi:10.36680/j.itcon.2021.047

Tallgren, M. V., Roupé, M., \& Johansson, M. (2021). 4D MODELLING USING VIRTUAL COLLABORATIVE PLANNING AND SCHEDULING. Journal of Information Technology in Construction (ITCON), 26, 763-782, doi:10.36680/j.itcon.2021.042

Wong, P. F., Chia, F. C., Kiu, M. S., \& Lou, E. C. W. (2020). Potential integration of blockchain technology into smart sustainable city (SSC) developments: a systematic review. Smart and Sustainable Built Environment, ahead-of-print(ahead-of-print). doi:10.1108/SASBE-09-2020-0140 